\title{
Challenges in cardiac device innovation: is neuroimaging an appropriate endpoint? Consensus from the 2013 Yale-UCL Cardiac Device Innovation Summit
}

\author{
Stephanie M Meller ${ }^{1}$, Andreas Baumbach², Szilard Voros ${ }^{3}$, Michael Mullen ${ }^{4}$ and Alexandra J Lansky ${ }^{1 *}$
}

\begin{abstract}
Background: Neurological events associated with transcatheter aortic valve implantation are major contributors to morbidity and mortality. Choosing an appropriate endpoint to determine neuroprotection device efficacy is a key difficulty inhibiting the translation of the innovation from the laboratory to the bedside. Cost and sample size limitations inhibit the feasibility of using the rate of clinical (such as stroke or other cerebral) events as the primary efficacy endpoint. This paper focuses on consensus opinions from the 2013 Yale-University College London (UCL) Device Innovation Summit.

Discussion: Neuroimaging, specifically diffusion-weighted magnetic resonance imaging (DW MRI), may serve as a surrogate endpoint for clinical studies detecting cerebral events in which cost and sample-size limitations prohibit the use of clinical outcomes. A major limitation of using imaging to prove efficacy in cardiac device studies is that no standardized endpoint exists. Ongoing trials investigating cerebral protection devices for transcatheter aortic valve implantation are utilizing and reporting various qualitative and quantitative DW MRI values; however, single lesion volume, number of new lesions, and total lesion volume have been found to be the most reproducible and prognostically important imaging measures.
\end{abstract}

Summary: DW MRI may be a useful surrogate endpoint for clinical studies detecting cerebral events to determine the device's success in neurological protection. Consensus from the 2013 Yale-UCL Device Innovation Summit specifically recommends the reporting of mean single lesion volume, number of new lesions, and total volume, and encourages European Union (EU)-US regulatory consensus in the guidance of implementing this endpoint.

\section{Background}

Neurological events contribute to the morbidity and mortality associated with transcatheter aortic valve implantation (TAVI). Neuroimaging, specifically diffusion-weighted magnetic resonance imaging (DW MRI), may be a useful tool for assessing clinical outcomes of both unprotected TAVI as well as in the evaluation of cerebral protection devices.

The current state of neuroprotection for TAVI is of great interest among inventors and clinicians involved in cardiac device development and implementation, and was

\footnotetext{
* Correspondence: Alexandra.Lansky@yale.edu

${ }^{1}$ Yale University School of Medicine and Yale Cardiovascular Research Group, 1 Church Street Suite \#330, PO Box 208017, New Haven, CT 06510, USA Full list of author information is available at the end of the article
}

thus a primary focus of the 2013 Yale-University College London (UCL) Cardiac Device Innovation Summit. This meeting provided a forum for engineers and clinicians to openly discuss the complexities of cardiac embolic protection devices, and address the unmet needs of the regulatory approval process to enhance percutaneous valvular device innovation and clinical implementation.

The 2013 Yale-UCL summit focused on secondgeneration TAVI, neuroprotection device development and evaluation as adjunct to TAVI, percutaneous mitral valve devices and left ventricular support devices, and novel percutaneous coronary devices including biodegradable stent technologies and targeted biologics. An expert faculty of Europe-based and US-based regulators, industry partners, funders, engineers and clinicians led various discussions

\section{Ciomed Central}

(C) 2013 Meller et al.; licensee BioMed Central Ltd. This is an open access article distributed under the terms of the Creative Commons Attribution License (http://creativecommons.org/licenses/by/2.0), which permits unrestricted use, distribution, and reproduction in any medium, provided the original work is properly cited. 
throughout the 2-day conference, which was publicized within the Yale and UCL campuses and open to all, with no registration fees. The meeting was sponsored by Yale University and UCL.

Choosing an appropriate endpoint to determine device efficacy is a key difficulty inhibiting the translation of the innovation from the laboratory to the bedside. The Yale-UCL summit developed consensus recommendations regarding the selection of study endpoints, specifically for clinical trials investigating strategies for neuroprotection in TAVI. Below, we will provide a brief discussion of TAVIrelated stroke and current strategies for neuroprotection, and provide our conclusions recommending neuroimaging, specifically DW MRI, as a cost-effective and potentially even clinically meaningful endpoint to investigate efficacy of cerebral protection devices for use in cardiac procedures.

\section{TAVI-related stroke}

There are several accepted therapies to treat severe aortic stenosis but each is associated with significant risks. The 'Placement of AoRTic TraNscathetER' PARTNER trial and other smaller studies have demonstrated the superiority of TAVI to standard medical therapy for inoperable patients with aortic stenosis and its non-inferiority to surgical valve replacement for high risk patients, with such findings evident up to 2 years post procedure [1,2]. Further implementation of TAVI is limited by the risk of stroke, a devastating contributor to morbidity and mortality in the typically older and relatively frailer patient population undergoing such endovascular procedures.

Indeed, the PARTNER trial demonstrated a two to three times higher risk of stroke with TAVI compared with standard medical therapy or surgery [1], and the rate of TAVI-related stroke is estimated to be between $0 \%$ to $11 \%$ [3-5], depending on patient and procedural characteristics. The US Food and Drug Administration (FDA) cited the rate of neurological adverse events as a significant concern in approving the Edwards SAPIEN device [6]. Importantly, advances in device technology have led to lower contemporary estimates of periprocedural stroke. In a recent metaanalysis of $>10,000$ patients, Eggebrecht et al. determined the incidence of stroke within the first $24 \mathrm{~h}$ of TAVI to be $1.5 \% \pm 1.4 \%$; other studies have found similar results $[7,8]$. Further, when compared to high-risk surgical cohorts, the rates of complications in TAVI may even be similar to those of surgical valve replacement $[9,10]$. Improved operator experience and smaller insertion profiles may also decrease the incidence of stroke below that reported in the PARTNER trial $[11,12]$.

The TAVI procedure involves the introduction of bulky devices into atherosclerotic arteries and a calcified aortic valve, and thus lends itself to cerebral embolization of plaque debris. The majority of TAVI-related strokes are in fact periprocedural and $>50 \%$ occur within the first $24 \mathrm{~h}$ of the procedure $[1,13]$. The cause of periprocedural neurological events during TAVI is probably multifactorial but the pattern of cerebral ischemia following the procedure suggests mechanical embolization of atherosclerotic debris $[13,14]$. It has been shown that the highest rates of cerebral embolization occur during valve positioning and implantation [15]. Key steps that pose major risk include balloon valvuloplasty, passage of a large-bore catheter, retrograde travel through the aortic arch, and crushing of the native valve leaflets [7]. Hypoperfusion due to rapid ventricular pacing during balloon valvuloplasty or valve implantation is also a possible contributor.

The importance of new lesions found on DW MRI, many of which are clinically silent, remains unclear; however, studies utilizing DW MRI have found new lesions in $58 \%$ to $91 \%$ of patients undergoing TAVI $[15,16]$. There is increasing evidence from studies not involving TAVI that the cumulative burden of ischemic brain injury may cause neuropsychological deficits, aggravate vascular dementia, and contribute to cognitive decline [17]. Notably, these studies have shown that the 5-year survival is considerably decreased for patients with vascular dementia compared with age-matched controls (39\% versus 75\%) [18]. However, though bright lesions on DW MRI are commonly associated with ischemic lesions, they can also be caused by migraines, seizures, or hypoglycemia, and these events may contribute to the positive DW MRI results seen in many patients undergoing TAVI.

The incidence of stroke within 30 days of the TAVI procedure is estimated to be between $1.7 \%$ to $6.7 \%$, and there continues to be an increased risk of stroke in the years following the procedure [1,19-21]. Post-procedural neurologic events are likely caused by patient comorbidities such as atrial fibrillation, hypertension and possibly atherosclerotic plaque or thrombus formation at the valve level. Post-procedural DW MRI would have no advantage in detecting or predicting such neurologic events.

Further, Kahlert et al. found that $80 \%$ of newly detected lesions on DW MRI demonstrated reversal during the 3-month follow-up period; however, apparent lesion reversal does not necessarily mean normalization of brain tissue [15]. In fact, animal studies have shown that even after reversal, neurons exhibit structural damage with histological staining suggesting that other non-neuronal cells may compensate for the alterations in fluid balance [22].

\section{Adjunctive pharmacology and neuroprotection devices for TAVI}

Given the increased risk of stroke associated with TAVI, both adjunctive pharmacotherapy to prevent thrombosis and neuroprotective devices may be indicated. The literature is scarce regarding the appropriate antithrombotic regimen for TAVI, and the few studies that have been conducted have focused both on antiplatelet therapy 
(including aspirin and clopidogrel) and anticoagulant agents (including bivalirudin and heparin). The only published clinical trial to date randomized 79 patients undergoing TAVI to receive a 300-mg loading dose of clopidogrel on the date of procedure plus post-procedural maintenance therapy consisting of 3 months of $75 \mathrm{mg}$ of clopidogrel daily plus aspirin $100 \mathrm{mg}$ lifetime or aspirin $100 \mathrm{mg}$ alone. The results demonstrated no clinical benefit from the addition of 3 months of clopidogrel maintenance therapy [23]. This finding is important for patients with chronic atrial fibrillation treated with daily warfarin and aspirin, who demonstrate a significantly increased bleeding risk with the addition of clopidogrel for catheterization procedures [24]. Based on the findings of the aforementioned clinical trial, aspirin therapy alone following TAVI is effective and may improve the safety of patients with atrial fibrillation undergoing the procedure. The 'Effect of BivaliRudin on Aortic Valve Intervention Outcomes' (BRAVO) 2/3 study will assess the safety and efficacy of using bivalirudin instead of unfractionated heparin in TAVI with the hypothesis that bivalirudin reduces bleeding rates and improves clinical outcomes relative to heparin [25].

In addition to antithrombotic therapy, patients undergoing TAVI may also benefit from the use of cerebral protection devices. The temporal pattern and location of cerebral infarcts and silent ischemic lesions following TAVI indicate periprocedural mechanical embolization as the most likely pathophysiologic mechanism of periprocedural stroke. We thus believe that there is a role for cerebral protection devices in preventing stroke associated with TAVI. The ideal protection device is safe, effective, easy to use, can accommodate various anatomies, demonstrates minimal interference with the TAVI procedure, and importantly, covers all three major cerebral inflow aortic arch vessels. Notably, using protection devices may make the TAVI procedure more cumbersome, complicated, and time consuming, and may thus drive up costs. Results from the 'Action in Diabetes and Vascular disease: PreterAx and DiamicroN Controlled Evaluation' (ADVANCE) study link procedural time with the incidence of stroke, suggesting that a fast and simple procedure may be one of the most important factors for stroke prevention (Johan Bosmans, University Hospital of Antwerp, Antwerp, Belgium, personal communication). In addition, lower contemporary stroke rates associated with TAVI raise the question of whether cerebral protection devices and/or adjunctive pharmacotherapy should be recommended for all patients undergoing the procedure. Future randomized controlled trials are needed to determine which patient groups would benefit from these preventative measures. If the increased stroke risk associated with TAVI remains an issue in the future, the implementation of embolic protection devices may be valuable in reducing both clinically evident and occult strokes; however, if further studies suggest that these risks have already been reduced, additional devices may not be warranted.

Current embolic protection devices under clinical investigation include the Edwards Embrella Embolic Deflector (Edwards Lifesciences, Irvine, CA, USA), the Keystone Heart TriGard ${ }^{\mathrm{Tm}}$ Embolic Deflection Device (Caesarea Business Park, Caesarea, Israel), and the Claret CE Pro ${ }^{\text {Tx }}$ (Claret Medical, Santa Rosa, CA, USA) (Table 1). While the Embrella and Claret CE Pro are only designed to protect the brachiocephalic and left common carotid arteries, the Keystone Heart device is designed to deflect debris away from all aortic arch cerebral inflow vessels (brachiocephalic, left common carotid, and left subclavian arteries) [26-28].

The only published human study of the Embrella device reports the results of its implantation in three patients undergoing TAVI and one patient undergoing BAV alone. Though no patient developed new neurological symptoms or stroke, a new 5-mm acute cortical infarct was found on predischarge cerebral MRI in the patient who had undergone BAV but remained asymptomatic [26]. Unpublished data of 38 endovascular cases with Embrella implantation from 4 sites in Germany and Canada reported the occurrence of 2 device-related adverse events (1 CVA attributed to malposition of the device, which resolved at discharge; and 1 episode of blurred vision, cause undetermined) and a $2.6 \%$ major adverse event rate. Comparison of DW MRI with unprotected historical controls demonstrated similar average numbers of lesions per subject ( 6.0 versus 4.69 [29] and 3.2 [16]) but a significant reduction in the average volume of lesions in protected subjects versus unprotected historical controls (5.9 cubic centimeters versus 0.394 cubic centimeters [29]) (John G Webb, St. Paul's Hospital, Vancouver, BC, Canada; personal communication).

Implantation of the Keystone Heart TriGard device in 15 patients resulted in no procedural complications and 1 patient suffering a transient ischemic attack 2 days after the procedure [28]. DW MRI showed 3.2 new cerebral lesions per patient in the study compared with 7.2 lesions per patient in a historical unprotected control group; however, lesion volumes were not reported [28]. In addition, a study involving 40 patients and the Claret CE Pro also revealed no periprocedural incidence of stroke with the device; however, neither DW MRI nor transcranial Doppler were performed. Results from the ongoing DEFLECT I trial will provide DW MRI data in patients undergoing TAVI with the TriGard device in place.

Results of the first in-human studies of neuroprotection devices show promise in reducing the occurrence of neurologic events and thus improving outcomes in TAVI. DW MRI has been used to indicate periprocedural cerebral ischemia after unprotected TAVI in numerous studies $[15,29,30]$. There are two published studies evaluating the Embrella and TriGard cerebral protection devices, which 
Table 1 Characteristics of current cerebral protection devices for transcatheter aortic valve implantation

\begin{tabular}{llll}
\hline Feature & Edwards Embrella Embolic Deflector [26] & Keystone Heart TriGard Embolic Deflection Device [28] & Claret CE Pro [27] \\
\hline Access & Radial & Femoral & Radial \\
Position & Aorta & Aorta & Brachiocephalic and LCC \\
Coverage area & Brachiocephalic and LCC & Brachiocephalic, LCC and LSC & Brachiocephalic and LCC \\
Mechanism & Deflection & Deflection & Capture \\
Size & $6 \mathrm{~F}$ & $9 \mathrm{~F}$ & $6 \mathrm{~F}$ \\
Pore Size & 100 microns & Approximately 200 microns & 140 microns \\
\hline
\end{tabular}

LCC left common carotid artery, LSC left subclavian artery.

present the mean or total number of new DW MRI lesions $[26,28]$; however, ongoing trials are studying mean or total volume of new lesions, as discussed in the following section. The use of various DW MRI endpoints to measure device efficacy implores us to consider if an imaging endpoint is appropriate and if so, then how to define it. The Yale-UCL summit evaluated these important questions and our conclusions are reported below.

\section{Discussion}

\section{Neuroimaging as an endpoint measure}

Neuroimaging modalities, specifically transcranial Doppler ultrasound (TCD) and DW MRI are useful for detecting acute ischemic stroke and have provided additional information about microembolization in TAVI. TCD uses low frequency pulsed sound to allow visualization of the circle of Willis vessels and can identify high-intensity transient signals (HITS) and microembolic signals (MES). Studies have found the detection of HITS in all patients undergoing TAVI and the majority of MES occurring during balloon valvuloplasty and valve delivery [31]. Unfortunately TCD is highly operator dependent and requires considerable skill and experience to attain accurate, reproducible results [32]. DW MRI is used to detect changes in the self-diffusion of water molecules associated with ischemic injury. Given its high sensitivity for detecting brain ischemia and widespread availability, DW MRI is a suitable method for monitoring neurovascular events during interventional procedures [33].

Choosing an appropriate endpoint for a clinical trial can be complex. In fact, between $10 \%$ to $15 \%$ of medical devices that enter the EU regulatory pathway lack relevant endpoints, which is considered grounds for objection. The penetration rate of devices in general, and in TAVI specifically, is significantly delayed in the US compared to Europe mostly due to FDA requirements for reasonable assurance of safety and effectiveness of a device prior to its approval [28].

For clinical trials investigating neuroprotection devices for use in cardiac procedures, the investigators must prove that the device is able to reduce the occurrence and/or severity of cerebral events. Ideally this would be accomplished by reporting an actual reduction in the rate of stroke, transient ischemic attack, and other neurologic events according to Valve Academic Research Consortium2 definitions [34]. Because the occurrence of TAVI-related stroke is relatively low $(<10 \%)$, a large sample size would be needed to detect a difference in clinical event rate with versus without a protection device. In addition to sample size requirements, the rising cost of clinical trials limits the feasibility of using relatively uncommon clinical events as trial efficacy endpoints. Further, silent ischemia accounts for the majority of lesions detected on neuroimaging following TAVI procedures. Using a clinical event endpoint to measure device success would miss the occurrence of these silent lesions, which are associated with cognitive decline and mortality $[17,18]$.

Neuroimaging, specifically DW MRI, may serve as a surrogate endpoint for clinical studies detecting cerebral events in which cost and sample size limitations prohibit the use of clinical outcomes (Table 2). DW MRI, which has sensitivity and specificity up to $92 \%$ and $97 \%$, respectively, combines features of conventional spin echo and gradient echo techniques to image the freedom of the diffusion of water molecules to identify restriction in diffusion, suggestive of cerebral ischemia [35]. In cytotoxic edema due to hypoxia, the redistribution of water from the extracellular to the intracellular space is visible within 0 to 5 days of the event (Figure 1). On DW MRI, normal tissue appears gray due to the Brownian motion and diffusion of water molecules, whereas restricted diffusion in the case of ischemia prevents the normal loss of MRI signal and thus appears white. A bright signal on DW MRI and a dark signal on the corresponding apparent diffusion coefficient map is characteristic of acute brain injury within 5 days.

One important issue to consider is that evidence for long-term consequences of lesions detected by DW MRI is lacking. Indeed, recent studies have implied that DW MRI lesions after TAVI are not related to self-sufficiency or mortality 1-year post procedure and that there may even be less cognitive decline post TAVI compared with surgery, despite a higher incidence of embolic lesions $[37,38]$. These studies are limited by small sample sizes but they suggest that there may limitations in utilizing DW MRI to evaluate TAVI outcomes.

Another major limitation of using DW MRI in clinical trials is that no clear definition of the endpoint exists. 
Table 2 Clinical trial endpoints that may be used to demonstrate cardiac device efficacy in neuroprotection

\begin{tabular}{|c|c|c|}
\hline Endpoint measure & Advantages & Disadvantages \\
\hline \multirow{3}{*}{$\begin{array}{l}\text { Incidence of clinical outcomes (such as stroke, } \\
\text { transient ischemic attack) }\end{array}$} & Clear indicator of neurologic events & Low incidence rate demands large sample size to observe effect \\
\hline & \multirow{2}{*}{$\begin{array}{l}\text { Can be reported in a standardized } \\
\text { fashion using the NIH stroke scale } \\
\text { and Modified Rankin scale. }\end{array}$} & Cost limitations may prohibit large sample size \\
\hline & & May miss silent/subtle clinical events \\
\hline \multirow{4}{*}{$\begin{array}{l}\text { Neuroimaging (such as diffusion-weighted } \\
\text { magnetic resonance imaging, transcranial } \\
\text { Doppler ultrasound) }\end{array}$} & Easy and reproducible & No standardized definition of endpoint \\
\hline & \multirow[t]{3}{*}{ Widely available } & Variation in reporting makes cross-study comparisons difficult \\
\hline & & $\begin{array}{l}\text { May be contraindicated in some patients } \\
\text { (for example, those with pacemakers) }\end{array}$ \\
\hline & & Radiographic interpretation may be subjective \\
\hline \multirow{5}{*}{$\begin{array}{l}\text { Biomarkers (such as S100ß, apolipoprotein A1, } \\
\text { neuron-specific enolase) }\end{array}$} & Easy & Validity not established \\
\hline & Reproducible & Normal range for certain patient populations unknown \\
\hline & Objective & Timing is critical \\
\hline & \multirow[t]{2}{*}{ Less biased } & Expensive \\
\hline & & Subject to laboratory errors \\
\hline
\end{tabular}
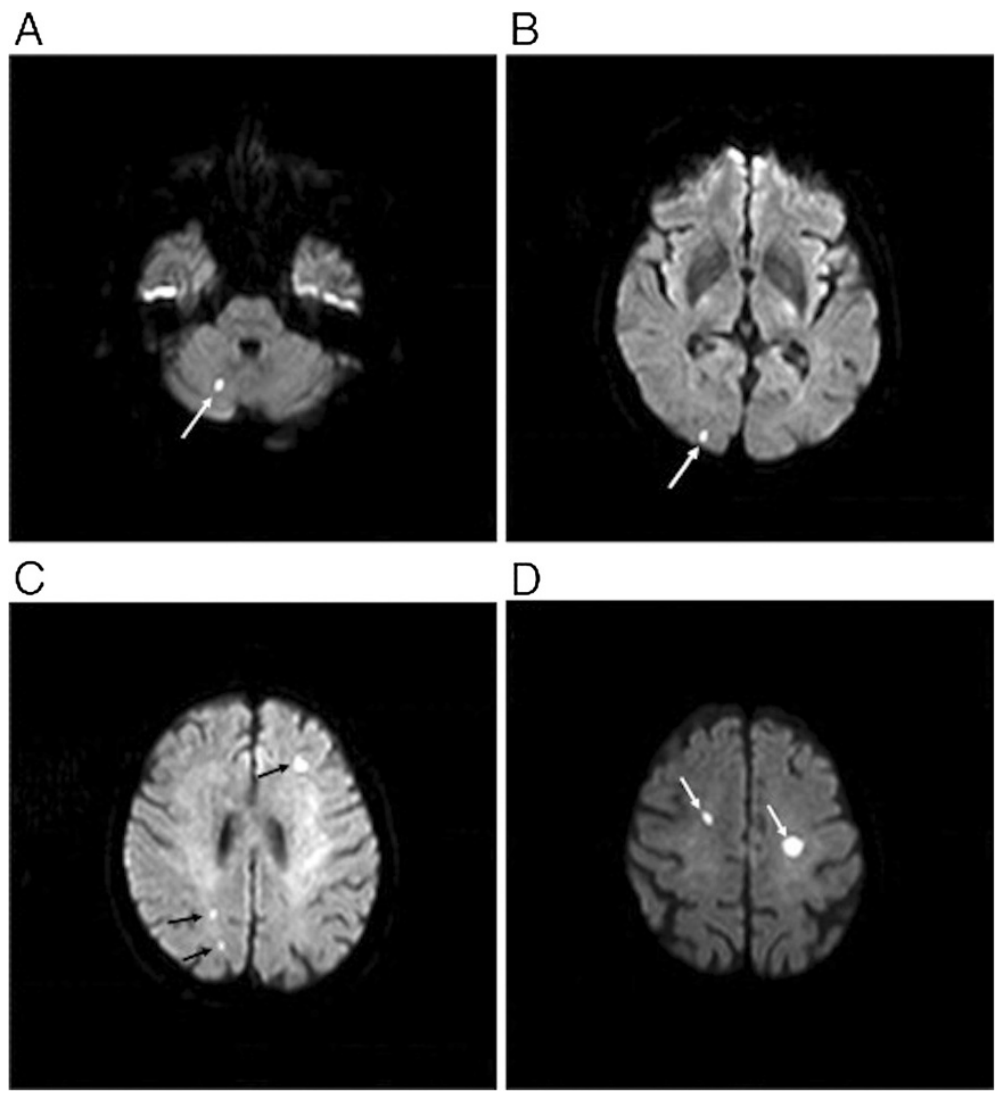

D

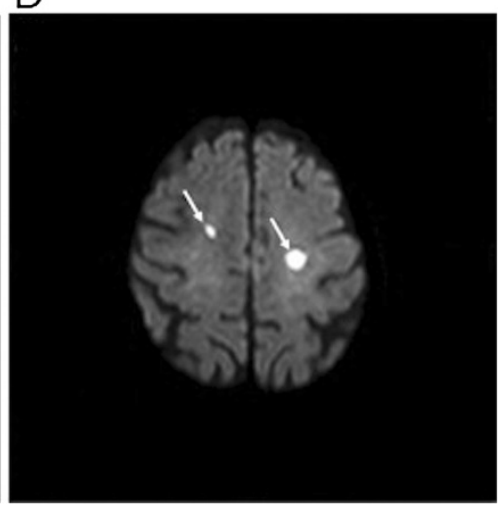

Figure 1 Diffusion-weighted magnetic resonance imaging (DW MRI) following transfemoral transcatheter aortic valve implantation in an 86-year-old patient. Multiple acute ischemic lesions in the right cerebellum ((A), white arrow), white occipital territory ((B), white arrow), left frontal and right parietal territories ((C), black arrows), and left and right frontal superior territories ((D), white arrows). Adapted with permission from Rodes-Cabau et al. J Am Coll Cardiol 2011, 57:18-28 [36]. 
Qualitative measurements include lesion number and vascular territory involved and quantitative measurements include total lesion volume, average lesion volume, and maximum lesion volume. All are key neuroimaging endpoint parameters to follow the efficacy of neuroprotection, however, the endpoint must be standardized to allow for cross-study comparison.

Ongoing clinical trials investigating cerebral protection devices for TAVI are utilizing various DW MRI measures to determine device efficacy. The ongoing Prospective Randomized Outcome Study in Patients Undergoing TAVI to Examine Cerebral Ischemia and Bleeding Complications (PROTAVI) trial, which is randomizing patients eligible for TAVI to undergo the procedure with or without the Embrella deflection device, will analyze the rate of new DW MRI brain lesions at 7 days post procedure. Likewise, the DEFLECT I trial is a single arm study enrolling up to 60 patients in the EU, Canada, and Brazil to undergo TAVI with the Keystone Heart TriGard in place using the presence of new DW MRI lesions post procedure compared with a historical control group as a measure of device success.

Although DW MRI lesion presence and rate of occurrence are being used as endpoints, total lesion volume is the most reproducible measurement when performed in an experienced core laboratory, and along with geographic location, provides the best measure of overall burden of ischemic injury, and may therefore be a more appropriate endpoint measure. Though it fails to identify the functional region of the brain involved, studies have identified DW MRI lesion volume as an independent predictor of clinical outcome after acute stroke [39,40]. Specifically, mean lesion volume has been correlated with mental changes and vascular dementia following endovascular procedures [41]. In contrast, the presence and number of DW MRI lesions are only likely to be clinically relevant if the individual lesion is large or in an area of functional significance [42]. Therefore, the Yale-UCL summit concluded that DW MRI lesion volume should be measured by independent core laboratory assessment with validated and reproducible methodology and should be included and reported in all clinical studies using DW MRI to investigate neuroprotection devices for use in TAVI. We recommend that single lesion volume, number of new ischemic lesions, and total lesion volume be measured.

Lastly, in 2011, the FDA issued draft guidance for clinical trial imaging endpoints for studies intending to confirm drug efficacy, recognizing that the use of imaging may assist in the assessment of safety and efficacy as well as patient eligibility. US regulatory requirements have been an impediment to early clinical testing of new devices, which US investigators have mostly outsourced overseas. During the Yale-UCL summit, the FDA expressed its goals to encourage medical device innovation, enhance regulatory science, and facilitate early feasibility clinical studies in the US. Consensus from the Yale-UCL summit called for validation of imaging endpoints in neuroprotection trials involving medical devices and encouraged European regulatory bodies and the FDA to work with the clinical and device industry to support this position.

\section{Summary}

In summary, stroke is a major contributor to morbidity and mortality in TAVI and the development of effective cerebral protection devices may optimize clinical outcomes. Though periprocedural outcomes may already be better than previously thought, it is still necessary to confirm the rates of neurological events in a consistent and reliable manner. Sample size requirements and rising costs of clinical trials are prohibitive to the use of clinical event rates as device efficacy endpoints. The 2013 Yale-UCL Summit developed consensus opinions regarding this topic. DW MRI may be a sensitive and specific surrogate endpoint for clinical studies detecting cerebral events to determine the device's success in neurological protection; however, further research is needed. Finally, for clinical trial investigators using DW MRI as an endpoint to detect cerebral events, we recommend the reporting of mean single lesion volume, number of new lesions, and total volume, as we have concluded that these values are the most reproducible and potentially even prognostically meaningful DW MRI measures.

\section{Abbreviations}

BAV: Balloon aortic valvuloplasty; CVA: Cerebrovascular accident; DW MRI: Diffusion-weighted magnetic resonance imaging; EU: European Union; FDA: US Food and Drug Administration; TAVI: Transcatheter aortic valve implantation; UCL: University College London.

\section{Competing interests}

The authors are investigators in the ongoing DEFLECT I trial (Keystone Heart, Ltd; Herzliya, Israel).

\section{Authors' contributions}

All authors have met the full criteria and requirements for authorship. SMM contributed in the conception and design of the manuscript as well as drafting of the manuscript. $A B$ supervised drafting of the background section, 'Review of adjunctive pharmacology and neuroprotection devices for TAVI' and SV supervised drafting of the sections involving neuroimaging. AJL and MM directed and led the Yale-UCL Summit, including the sessions discussed in this article. All authors contributed in revising the manuscript critically for intellectual content. All authors have provided final approval of the manuscript submitted.

\section{Authors' information}

AJL and MM organized and led the 2013 Yale-UCL Cardiac Device Innovation Summit, which the remaining authors participated in. AJL is an associated Professor of Cardiology at Yale University School of Medicine and directs the Yale Cardiovascular Research Group (YCRG) and the Yale Valve Program. MM is a consultant cardiologist at the Heart Hospital, University College London, and leads the Structural Heart Intervention program. SMM is a medical student at Yale University School of Medicine conducting research with AJL at YCRG. AB is a consultant cardiologist at University Hospitals Bristol in the UK and heads clinical research in the Department of Cardiology there. SV is an Associate Professor of Medicine/Cardiology and Radiology, and Director of 
Advanced Cardiovascular MR and CT Research at the Department of Radiology and Cardiology at Stony Brook University Medical Center.

\section{Author details}

'Yale University School of Medicine and Yale Cardiovascular Research Group, 1 Church Street Suite \#330, PO Box 208017, New Haven, CT 06510, USA. ${ }^{2}$ The Bristol Heart Institute, University Hospitals Bristol NHS Foundation Trust, Bristol, UK. ${ }^{3}$ Stony Brook University Medical Center, Stony Brook, NY, USA. ${ }^{4}$ The Heart Hospital, University College London, London, UK.

Received: 25 March 2013 Accepted: 22 November 2013 Published: 11 Dec 2013

\section{References}

1. Leon MB, Smith CR, Mack M, Miller DC, Moses JW, Svensson LG, Tuzcu EM, Webb JG, Fontana GP, Makkar RR, Brown DL, Block PC, Guyton RA, Pichard AD, Bavaria JE, Herrmann HC, Douglas PS, Petersen JL, Akin JJ, Anderson WN, Wang D, Pocock S: Transcatheter aortic-valve implantation for aortic stenosis in patients who cannot undergo surgery. N Engl J Med 2010, 363:1597-1607.

2. Kodali SK, Williams MR, Smith CR, Svensson LG, Webb JG, Makkar RR, Fontana GP, Dewey TM, Thourani VH, Pichard AD, Fischbein M, Szeto WY, Lim S, Greason KL, Teirstein PS, Malaisrie SC, Douglas PS, Hahn RT, Whisenant B, Zajarias A, Wang D, Akin JJ, Anderson WN, Leon MB: Two-year outcomes after transcatheter or surgical aortic-valve replacement. N Engl J Med 2012, 366:1686-1695.

3. Masson JB, Kovac J, Schuler G, Ye J, Cheung A, Kapadia S, Tuzcu ME, Kodali S, Leon MB, Webb JG: Transcatheter aortic valve implantation: review of the nature, management, and avoidance of procedural complications. JACC Cardiovasc Interv 2009, 2:811-820.

4. Nuis RJ, Piazza N, Van Mieghem NM, Otten AM, Tzikas A, Schultz CJ, van der Boon R, van Geuns RJ, van Domburg RT, Koudstaal PJ, Kappetein AP, Serruys PW, de Jaegere PP: In-hospital complications after transcatheter aortic valve implantation revisited according to the valve academic research consortium definitions. Catheter Cardiovasc Interv 2011, 78:457-467.

5. Lefevre F, Koskela J, Hubert J, Kraigher H, Longauer R, Olrik DC, Schuler S, Bozzano M, Alizoti P, Bakys R, Baldwin C, Ballian D, Black-Samuelsson S, Bednarova D, Bordacs S, Collin E, De Cuyper B, De Vries SM, Eysteinsson T, Frydl J, Haverkamp M, Ivankovic M, Konrad H, Koziol C, Maaten T, Paino EN, Ozturk H, Pandeva ID, Parnuta G, Pilipovic A, et al: Dynamic conservation of forest genetic resources in 33 European countries. Conserv Biol 2013, 27:373-384.

6. Dvir D, Barbash IM, Ben-Dor I, Okubagzi P, Satler LF, Waksman R, Pichard AD: The development of transcatheter aortic valve replacement in the USA. Arch Cardiovasc Dis 2012, 105:160-164

7. Eggebrecht $\mathrm{H}$, Schmermund A, Voigtlander T, Kahlert $\mathrm{P}$, Erbel R, Mehta RH: Risk of stroke after transcatheter aortic valve implantation (TAVI): a meta-analysis of 10,037 published patients. Eurolntervention 2012, 8:129-138.

8. Khatri PJ, Webb JG, Rodes-Cabau J, Fremes SE, Ruel M, Lau K, Guo H, Wijeysundera HC, Ko DT: Adverse effects associated with transcatheter aortic valve implantation: a meta-analysis of contemporary studies. Ann Intern Med 2013, 158:35-46.

9. Vasques F, Messori A, Lucenteforte E, Biancari F: Immediate and late outcome of patients aged 80 years and older undergoing isolated aortic valve replacement: a systematic review and meta-analysis of 48 studies. Am Heart J 2012, 163:477-485.

10. Panchal HB, Ladia V, Desai S, Shah T, Ramu V: A meta-analysis of mortality and major adverse cardiovascular and cerebrovascular events following transcatheter aortic valve implantation versus surgical aortic valve replacement for severe aortic stenosis. Am J Cardiol 2013, 112:850-860

11. Avanzas P, Munoz-Garcia AJ, Segura J, Pan M, Alonso-Briales JH, Lozano I, Moris C, Suarez de Lezo J, Hernandez-Garcia JM: Percutaneous implantation of the CoreValve self-expanding aortic valve prosthesis in patients with severe aortic stenosis: early experience in Spain. Rev Esp Cardiol 2010, 63:141-148.

12. Gurvitch R, Tay EL, Wijesinghe N, Ye J, Nietlispach F, Wood DA, Lichtenstein S, Cheung A, Webb JG: Transcatheter aortic valve implantation: lessons from the learning curve of the first 270 high-risk patients. Catheter Cardiovasc Interv 2011, 78:977-984.

13. Tay EL, Gurvitch R, Wijesinghe N, Nielispach F, Wood D, Cheung A, Ye J, Lichtenstein SV, Carere R, Thompson C, Webb JG: A high-risk period for cerebrovascular events exists after transcatheter aortic valve implantation. JACC Cardiovasc Interv 2011, 4:1290-1297.

14. Arnold M, Schulz-Heise S, Achenbach S, Ott S, Dorfler A, Ropers D, Feyrer R, Einhaus F, Loders S, Mahmoud F, Roerick O, Daniel WG, Weyand M, Ensminger SM, Ludwig J: Embolic cerebral insults after transapical aortic valve implantation detected by magnetic resonance imaging. JACC Cardiovasc Interv 2010, 3:1126-1132.

15. Kahlert $P$, Knipp SC, Schlamann M, Thielmann M, Al-Rashid F, Weber M, Johansson U, Wendt D, Jakob HG, Forsting M, Sack S, Erbel R, Eggebrecht H: Silent and apparent cerebral ischemia after percutaneous transfemoral aortic valve implantation: a diffusion-weighted magnetic resonance imaging study. Circulation 2010, 121:870-878.

16. Astarci P, Glineur D, Kefer J, D'Hoore W, Renkin J, Vanoverschelde JL, El Khoury G, Grandin C: Magnetic resonance imaging evaluation of cerebral embolization during percutaneous aortic valve implantation: comparison of transfemoral and trans-apical approaches using Edwards Sapiens valve. Eur J Cardiothorac Surg 2011, 40:475-479.

17. Meller SM, Baumbach A, Brickman AM, Lansky AJ: Clinical implications for diffusion-weighted MRI brain lesions associated with transcatheter aortic valve replacement. Catheter Cardiovasc Interv. In press.

18. Brodaty H, McGilchrist C, Harris L, Peters KE: Time until institutionalization and death in patients with dementia. Role of caregiver training and risk factors. Arch Neurol 1993, 50:643-650

19. Bleiziffer S, Mazzitelli D, Opitz A, Hettich I, Ruge H, Piazza N, Lange R: Beyond the short-term: clinical outcome and valve performance 2 years after transcatheter aortic valve implantation in 227 patients. J Thorac Cardiovasc Surg 2012, 143:310-317.

20. Ussia GP, Barbanti M, Petronio AS, Tarantini G, Ettori F, Colombo A, Violini R, Ramondo A, Santoro G, Klugmann S, Bedogni F, Maisano F, Marzocchi A, Poli A, De Carlo M, Napodano M, Fiorina C, De Marco F, Antoniucci D, de Cillis E, Capodanno D, Tamburino C: Transcatheter aortic valve implantation: 3-year outcomes of self-expanding corevalve prosthesis. Eur Heart J 2012, 33:969-976.

21. Wendler O, Thielmann M, Schroefel H, Rastan A, Treede H, Wahlers T, Eichinger W, Walther T: Worldwide experience with the 29-mm Edwards SAPIEN XTTM transcatheter heart valve in patients with large aortic annulus. Eur J Cardiothorac Surg 2013, 43:371-377.

22. Ringer TM, Neumann-Haefelin T, Sobel RA, Moseley ME, Yenari MA: Reversal of early diffusion-weighted magnetic resonance imaging abnormalities does not necessarily reflect tissue salvage in experimental cerebral ischemia. Stroke 2001, 32:2362-2369.

23. Ussia GP, Scarabelli M, Mule M, Barbanti M, Sarkar K, Cammalleri V, Imme S, Aruta P, Pistritto AM, Gulino S, Deste W, Capodanno D, Tamburino C: Dual antiplatelet therapy versus aspirin alone in patients undergoing transcatheter aortic valve implantation. Am J Cardiol 2011, 108:1772-1776.

24. Hansen ML, Sorensen R, Clausen MT, Fog-Petersen ML, Raunso J, Gadsboll N, Gislason GH, Folke F, Andersen SS, Schramm TK, Abildstrom SZ, Poulsen HE, Kober L, Torp-Pedersen C: Risk of bleeding with single, dual, or triple therapy with warfarin, aspirin, and clopidogrel in patients with atrial fibrillation. Arch Intern Med 2010, 170:1433-1441.

25. Sergie Z, Lefevre T, Van Belle E, Kakoulides S, Baber U, Deliargyris EN, Mehran R, Grube E, Reinohl J, Dangas GD: Current periprocedural anticoagulation in transcatheter aortic valve replacement: could bivalirudin be an option? Rationale and design of the BRAVO 2/3 studies. J Thromb Thrombolysis 2013, 35:483-493.

26. Nietlispach F, Wijesinghe N, Gurvitch R, Tay E, Carpenter JP, Burns C, Wood DA, Webb JG: An embolic deflection device for aortic valve interventions. JACC Cardiovasc Interv 2010, 3:1133-1138.

27. Naber CK, Ghanem A, Abizaid AA, Wolf A, Sinning JM, Werner N, Nickenig G, Schmitz T, Grube E: First-in-man use of a novel embolic protection device for patients undergoing transcatheter aortic valve implantation. Eurolntervention 2012, 8:43-50.

28. Onsea K, Agostoni P, Samim M, Voskuil M, Kluin J, Budde R, Hendrikse J, Ramjankhan F, van Klarenbosch J, Doesburg P, Sieswerda G, Stella P: First-in-man experience with a new embolic deflection device in transcatheter aortic valve interventions. Eurolntervention 2012, 8:51-56.

29. Ghanem A, Muller A, Nahle CP, Kocurek J, Werner N, Hammerstingl C, Schild HH, Schwab JO, Mellert F, Fimmers R, Nickenig G, Thomas D: Risk and fate of cerebral embolism after transfemoral aortic valve implantation: a prospective pilot study with diffusion-weighted magnetic resonance imaging. J Am Coll Cardiol 2010, 55:1427-1432 
30. Knipp SC, Matatko N, Schlamann M, Wilhelm H, Thielmann M, Forsting M, Diener $\mathrm{HC}$, Jakob H: Small ischemic brain lesions after cardiac valve replacement detected by diffusion-weighted magnetic resonance imaging: relation to neurocognitive function. Eur J Cardiothorac Surg 2005, 28:88-96.

31. Drews T, Pasic M, Buz S, Unbehaun A, Dreysse S, Kukucka M, Mladenow A Hetzer R: Transcranial Doppler sound detection of cerebral microembolism during transapical aortic valve implantation. Thorac Cardiovasc Surg 2011, 59:237-242.

32. Sarkar S, Ghosh S, Ghosh SK, Collier A: Role of transcranial Doppler ultrasonography in stroke. Postgrad Med J 2007, 83:683-689.

33. Lovblad KO, Pluschke W, Remonda L, Gruber-Wiest D, Do DD, Barth A, Kniemeyer HW, Bassetti C, Mattle HP, Schroth G: Diffusion-weighted MRI for monitoring neurovascular interventions. Neuroradiology 2000, 42:134-138.

34. Kappetein AP, Head SJ, Genereux P, Piazza N, van Mieghem NM, Blackstone EH, Brott TG, Cohen DJ, Cutlip DE, van Es GA, Hahn RT, Kirtane AJ, Krucoff MW, Kodali S, Mack MJ, Mehran R, Rodes-Cabau J, Vranckx P, Webb JG, Windecker S, Serruys PW, Leon MB: Updated standardized endpoint definitions for transcatheter aortic valve implantation: the valve academic research consortium-2 consensus document (VARC-2). Eur J Cardiothorac Surg 2012, 42:S45-S60.

35. Chalela JA, Kidwell CS, Nentwich LM, Luby M, Butman JA, Demchuk AM, Hill MD, Patronas N, Latour L, Warach S: Magnetic resonance imaging and computed tomography in emergency assessment of patients with suspected acute stroke: a prospective comparison. Lancet 2007, 369:293-298.

36. Rodes-Cabau J, Dumont E, Boone RH, Larose E, Bagur R, Gurvitch R, Bedard F, Doyle D, De Larochelliere R, Jayasuria C, Villeneuve J, Marrero A, Cote M, Pibarot P, Webb JG: Cerebral embolism following transcatheter aortic valve implantation: comparison of transfemoral and transapical approaches. J Am Coll Cardiol 2011, 57:18-28.

37. Ghanem A, Muller A, Sinning JM, Kocurek J, Becker BV, Vogel M, Vasa-Nicotera M, Hammerstingl C, Schwab JO, Nahle CP, Thomas D, Wagner M, Grube E, Werner N, Nickenig G: Prognostic value of cerebral injury following transfemoral aortic valve implantation. Eurolntervention 2013, 8:1296-1306.

38. Knipp SC, Kahlert $P$, Jokisch D, Schlamann M, Wendt D, Weimar C, Jakob H, Thielmann M: Cognitive function after transapical aortic valve implantation: a single-centre study with 3-month follow-up. Interact Cardiovasc Thorac Surg 2013, 16:116-122.

39. Thijs VN, Lansberg MG, Beaulieu C, Marks MP, Moseley ME, Albers GW: Is early ischemic lesion volume on diffusion-weighted imaging an independent predictor of stroke outcome? A multivariable analysis. Stroke 2000, 31:2597-2602

40. Lovblad KO, Baird AE, Schlaug G, Benfield A, Siewert B, Voetsch B, Connor A, Burzynski C, Edelman RR, Warach S: Ischemic lesion volumes in acute stroke by diffusion-weighted magnetic resonance imaging correlate with clinical outcome. Ann Neurol 1997, 42:164-170.

41. Choi SH, Na DL, Chung CS, Lee KH, Na DG, Adair JC: Diffusion-weighted MRI in vascular dementia. Neurology 2000, 54:83-89.

42. Chodosh EH, Foulkes MA, Kase CS, Wolf PA, Mohr JP, Hier DB, Price TR, Furtado JG Jr: Silent stroke in the NINCDS stroke data bank. Neurology 1988, 38:1674-1679.

10.1186/1741-7015-11-257

Cite this article as: Meller et al:: Challenges in cardiac device innovation: is neuroimaging an appropriate endpoint? Consensus from the 2013

Yale-UCL Cardiac Device Innovation Summit. BMC Medicine 2013, 11:257

\section{Submit your next manuscript to BioMed Central and take full advantage of:}

- Convenient online submission

- Thorough peer review

- No space constraints or color figure charges

- Immediate publication on acceptance

- Inclusion in PubMed, CAS, Scopus and Google Scholar

- Research which is freely available for redistribution

Submit your manuscript at www.biomedcentral.com/submit
C Biomed Central 